\title{
Effects of bagging or the combination of umbrella and bag treatments on anthocyanin accumulation in the berry skin of 'Kyoho' (Vitis labruscana) Grape
}

\author{
Si-Hong ZHOU ${ }^{1}$ (D), Rong-Rong GUO ${ }^{1}$, Rong-Fu WEI ${ }^{1}$, Jin-Biao LIU ${ }^{1}$, Huan YU ${ }^{1}$, Xiao-Fang SHI ${ }^{1}$, Ying ZHANG ${ }^{1}$, \\ Tai-Li XIE ${ }^{1}$, Guo CHENG ${ }^{1 *}$
}

\begin{abstract}
The object of this study was to investigate the influence of bagging or the combination of umbrella and bags on berry composition, especially anthocyanin accumulation, in 'Kyoho' (V. labruscana) berry skins. Five different colors and bag materials commonly used in production were chosen for this study: white, green, yellow, nonwoven and transparent, and the umbrellas were made of plastic material. The composition and content of anthocyanins in the berry skin of 'Kyoho' were analyzed by HPLC-MS. The results showed that bagging or a combination of umbrella and bags on anthocyanin concentration in 'Kyoho' grapes showed inconsistent effects that depended on the colors and materials of the bags and the use of an umbrella or not. Compared with the control, the inhibition effects of white, green and yellow bags on the soluble solids content and the total and individual anthocyanin concentrations in 'Kyoho' grapes reached significant levels; effects of green and yellow bags were the most significant among them. The plastic umbrella used in this study also presented a lower relative light intensity and produced more evencolored clusters. White, green, and yellow bags and combinations of umbrella and bags significantly increased some stable anthocyanin proportions to varying degrees, such as coumaroylated and methylated anthocyanins, compared to the control.
\end{abstract}

Keywords: bagging; umbrella; anthocyanin; 'Kyoho'; grape.

Practical Application: To provide a reference for anthocyanin characteristics and high-quality production of 'Kyoho' grapes, from the perspective of bagging or the combination of umbrella and bags.

\section{Introduction}

Anthocyanins contribute to the predominant pigments of red grapes and wine. There are several anthocyanins found in grapes, including cyanidin, peonidin, delphinidin, petunidin, and malvidin-derived pigments, the relative proportions of which are known to vary by cultivar (Tarara et al., 2008). Anthocyanins are influenced by environmental factors and viticultural practices. In grapes, there have been a number of reports of light exposure or shading affecting anthocyanin accumulation (Matus et al., 2009; Li et al., 2013; Sun et al., 2017).

'Kyoho', a hybrid of $V$. labrusca and V. vinifera, is a medium-season, attractive, tetraploid grape. 'Kyoho' is one of the most popular table grape cultivars, introduced to China in 1959. It was received favorably by consumers due to its large, succulent berries and crisp eating quality (Wang et al., 2001; Wang et al., 2012). Several previous studies have shown that the rotting rate and pesticide application decreased after bagging, and 'Kyoho' fruit presented clean and even color skins and higher soluble solids concentrations. Thus, fruit bagging effectively improves the economic character of the fruit commodity. Most research has focused on the effect of shading on table grape quality by using bags, boxes and sunshade nets (Gao \& Cahoon, 1994; Fujita et al., 2007; Koyama \& Goto-Yamamoto, 2008; Son \& Lee, 2008; Li et al., 2013) and analyzed their inner and exterior qualities.

With regard to the effects of shading on anthocyanin accumulation in grape berries, many studies have been conducted.
Decreased exposure to light generally inhibits anthocyanin accumulation in grape berries (Jeong et al., 2004; Koyama \& Goto-Yamamoto, 2008). Li et al. (2013) reported that clusters excluded from sunlight from fruit set to approximately one week preveraison exhibited significantly higher total anthocyanins as well as various anthocyanins than the control. Downey et al. (2004) reported that shading had no significant effect on the levels of anthocyanins in ripe 'Shiraz' berries. However, the effects of different bags or the combinations of umbrellas and bags on the anthocyanin composition and concentration of grapes have not yet been studied.

In this work, we used bags with different colors and textures at the veraison stage and the combinations of an umbrella and bags, which are commonly used in table grape production. The purpose was to determine the effect of bagging and umbrella+bagging at veraison on berry composition, especially anthocyanin accumulation.

\section{Materials and methods}

\subsection{Plant materials and experimental design}

The present investigation was conducted in 2016 on 11-year-old 'Kyoho' grapevines ( V. labruscana). All were located in the experimental vineyard of the Grape and Wine Research Institute, Guangxi Agriculture Academy of Sciences, China. 
The vines were planted under a drip irrigation system, fertilized and managed for diseases and insects by standard procedures, spaced $2.0 \times 3.0 \mathrm{~m}$, and grown by overhead trellis (star-shaped) cultivation. All vines were cultivated with rain shelter, and the grapes were hand harvested at technological ripeness in 2016. In this study, we focused on 20 grapevines and used approximately 20 grape clusters for each treatment. Approximately 60 berries were randomly sampled from the 20 grape clusters for each treatment (20 per replicate). Sampling was conducted on July 11 (4 weeks after veraison) of the 2016 growing season.

\subsection{Bagging and the combination of umbrella and bag treatments}

At fruit set, 20 vines were selected on the basis of uniformity of shoot growth and cluster development. Nine treatments were randomly assigned to each vine (Figure S1 - Supplementary Material), Control: clusters exposed to sunlight during the entire developmental period; T1: clusters excluded from sunlight from the beginning veraison ( 8 weeks after anthesis) by use of white bags; T2: clusters excluded from sunlight from the beginning veraison ( 8 weeks after anthesis) by use of green bags; T3: clusters excluded from sunlight from the beginning veraison (8 weeks after anthesis) by use of yellow bags; T4: clusters excluded from sunlight from the beginning veraison (8 weeks after anthesis) by use of non-woven bags; T5: clusters excluded from sunlight from the beginning veraison ( 8 weeks after anthesis) by use of transparent bags; T6: clusters excluded from sunlight from the beginning veraison ( 8 weeks after anthesis) by use of umbrellas and white bags; T7: clusters excluded from sunlight from the beginning veraison ( 8 weeks after anthesis) by use of umbrellas and non-woven bags; T8: clusters excluded from sunlight from the beginning veraison ( 8 weeks after anthesis) by use of umbrellas and transparent bags. In addition, the relative light intensity through the bag material was measured by a photometer (SMART SENSOR, China).

\subsection{Physicochemical properties measurements}

The control and treated clusters were sampled at maturity. Harvested berries were placed in plastic bags and transported on ice to the laboratory. Thirty berries (10 per replicate) were used to measure berry fresh weight, skin weight, edible rate, vertical diameter, lateral diameter, total soluble solids (TSS) and titratable acidity (TA).

\subsection{Anthocyanin analysis}

The extraction of anthocyanins in grape skins and the HPLC-MS analysis were carried out according to the previously published method of $\mathrm{He}$ et al. (2010). An Agilent 1100 series LC-MSD trap VL (Agilent, Santa Clara, CA, USA), equipped with a G1379A degasser, a G1312BA QuatPump, a G1313A ALS, a G1316A column, a G1315A DAD and a Kromasil 100-5 C18 column $(250 \times 4.6 \mathrm{~mm}, 5 \mu \mathrm{m})$ was used for anthocyanins detection. A flow rate of $1 \mathrm{~mL} / \mathrm{min}$ at ambient temperature was used. Solvent A was $2 \%(\mathrm{v}: \mathrm{v})$ formic and $6 \%$ acetonitrile in water, and solvent B was acetonitrile containing $2 \%$ formic acid and $44 \%$ water. Proportions of solvent B varied as follows:
$1-18 \mathrm{~min}, 10 \%$ to $25 \%$; $18-20 \mathrm{~min}, 25 \%$; $20-30 \mathrm{~min}, 25 \%$ to $40 \%$; $30-35 \mathrm{~min}, 40 \%$ to $70 \%$ and $35-40 \mathrm{~min}, 70 \%$ to $100 \%$. Injection volumes were $30 \mu \mathrm{L}$, and the detection wavelength was $525 \mathrm{~nm}$. The column temperature was $50^{\circ} \mathrm{C}$. MS conditions were as follows: Electrospray ionisation (ESI) interface, positive ion model, 30 psi nebulizer pressure, $12 \mathrm{~mL} / \mathrm{min}$ dry gas flow rate, $300{ }^{\circ} \mathrm{C}$ dry gas temperature, and scans at m/z 100-1500. Anthocyanins were quantified at $525 \mathrm{~nm}$ as malvidin-3-O-glucoside using calibration curves obtained within a concentration range between 0.5 and $1000 \mathrm{mg} / \mathrm{L}$, with linear correlation coefficients greater than 0.997. Both standards and samples were determined in triplicate.

\section{Results}

\subsection{Relative light intensity}

Relative light intensity through the bag material was observed to be more or less than that outside the bag at different rates, and $\mathrm{T} 3 \mathrm{had}$ only an approximately $7 \%$ relative light intensity (Figure 1). T7 and T8 exhibited lower relative light intensity than T4 and T5, respectively. Thus, umbrellas exhibited some sunlight shading effect. However, T4 and T5 showed significantly higher relative light intensity than the control and other treatments.

\subsection{Berry weight and composition}

The fresh weight of berries and skins for T4 tended to be the lowest, and the differences with the control were statistically significant (Table S1). T1, T3, T5, T6, T7 and T8 did not significantly influence berry fresh weight, although their skin fresh weights were lower than those of the control. T3, T4, T5 and T6 significantly increased in the edible rate, but there were no significant differences between the other treatments and the control. The vertical diameters of berries under T1, T2, T4 and T5 were significantly lower than those of the control. However, all the treatments had no significant influence on the lateral diameter of berries. From the data, T1, T2, T3 and T6 significantly

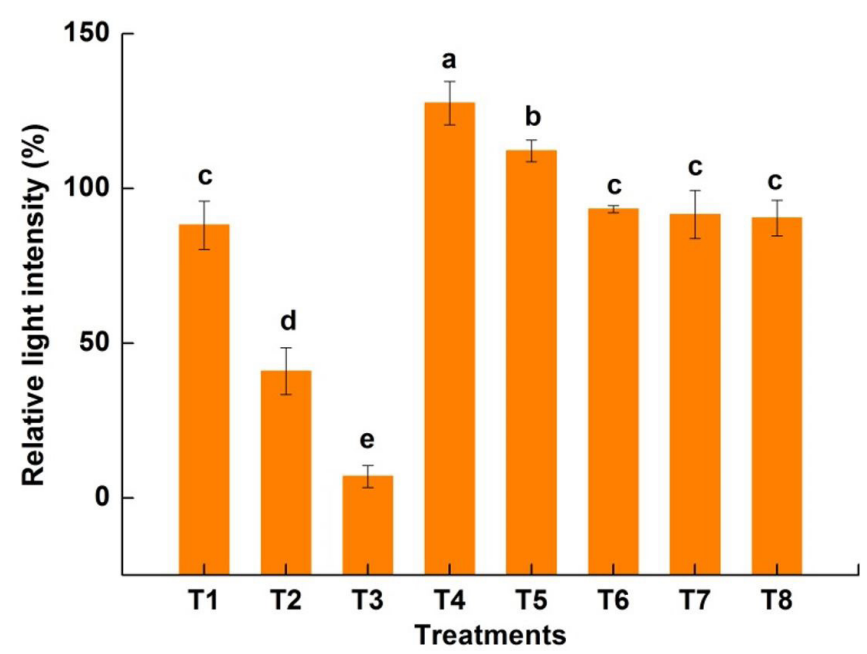

Figure 1. Relative light intensity of different treatments. The different letters above a set of columns indicate significant differences at the $5 \%$ level $(\mathrm{P}<0.05)$. 
decreased TSS, and there were no significant differences between the other treatments and the control. In addition, the TA levels were similar for both the control and all shading treatments.

\subsection{Identification of anthocyanins in the skin of 'Kyoho' grape}

Twenty anthocyanins were identified in the skin of 'Kyoho' grapes with the application of HPLC-MS, regardless of the treatments (Table S2). The chromatography and mass spectrometry information of these anthocyanins are presented in Table S2. They comprised a series of monoglucoside, diglucosides and their acylated (acetylated or coumaroylated) derivatives for all the grape samples analyzed. Peaks numbered 1, 3, 4 correspond to the diglucosides of petunidin, peonidin and malvidin. Peaks 2 and 5-7 represent the monoglucosides of delphinidin, cyanidin, petunidin, peonidin and malvidin. Peaks 8 and 15 correspond to acetylated diglucosides and the monoglucoside of malvidin, and peaks 9-14 and 16-20 correspond to coumaroylated diglucosides and the monoglucosides of delphinidin, cyanidin, petunidin, peonidin and malvidin.

\subsection{Anthocyanin concentration in the skin of 'Kyoho' grape}

Via cluster analysis, these grape samples under different treatments were broadly clustered into two groups according to their characteristic anthocyanin concentrations and compositions (Figure 2). Specifically, the first group of four concerned T1, T2, T3 and T6, which presented lower concentrations of most of anthocyanins compared with the second group (control, T4, T5, T7 and T8). The total anthocyanin concentrations of the grapes under different treatments decreased in the following order: $\mathrm{T} 7>$ control $>\mathrm{T} 8>\mathrm{T} 4>\mathrm{T} 6>\mathrm{T} 5>\mathrm{T} 1>\mathrm{T} 3>\mathrm{T} 2$. When the individual compounds were considered, the concentrations of almost all the anthocyanins showed the greatest reduction in grapes under T2 and T3. In addition, grapes under T1 and T6 contained lower anthocyanin concentrations compared with the

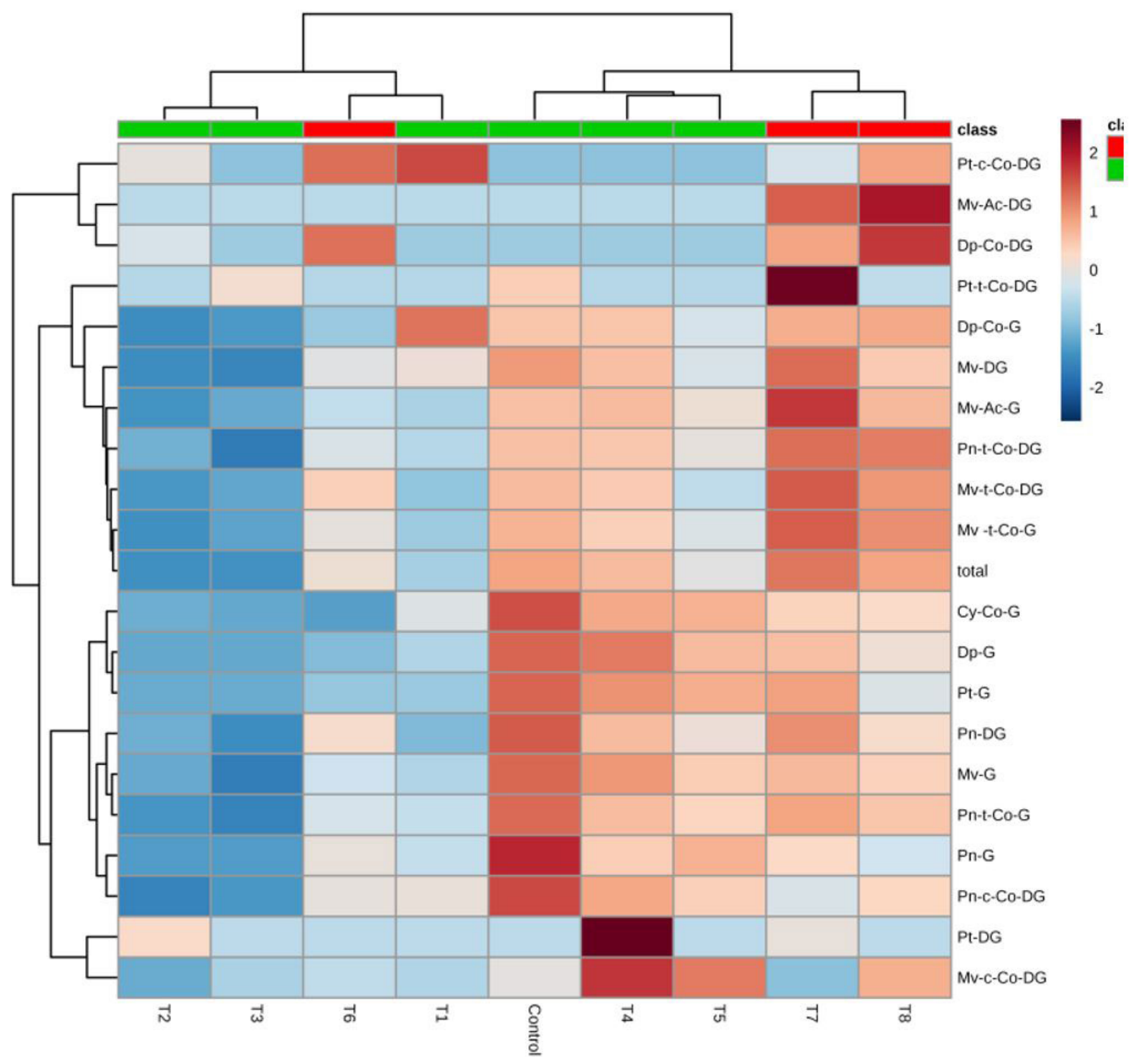

Figure 2. Cluster analysis of total anthocyanin concentration and concentration of each anthocyanin in grapes. 
control except Pt-c-Co-DG, Dp-Co-DG and Dp-Co-G. T4 grapes had higher concentrations of Pt-DG and Mv-c-Co-DG than the other treatments and the control, as the others exhibited lower concentrations. Mv-Ac-DG, Dp-Co-G, Mv-DG, Mv-Ac-G, Mv-t-Co-DG and Mv-t-Co-G showed the highest concentrations in grapes from T7 and T8. The grapes of T7 had the highest concentrations of Pn-t-Co-DG. However, all the treatments decreased Cy-Co-G, Dp-G, Pt-G, Pn-DG, Mv-G, Pn-t-Co-DG, Pn-G and Pn-c-Co-DG.

\subsection{Diversity of different modified anthocyanins}

The changes in the proportions and concentrations of different modified anthocyanins and the total anthocyanin concentration are shown in Table 1 and Figure 3, respectively. With regard to total anthocyanin concentration, there were no significant differences between T4, T5, T6, T7 and T8 (Table 1). Notably, total anthocyanin concentrations of grapes under T1, T2 and T3 were significantly lower than that in the control. Regarding mature clusters from different treatments, T2, T3 and T5 clusters showed a much lighter color than the control (Figure S2). T2 and T3 showed significantly higher proportions of diglucosides than the control. However, there were no significant differences in diglucosides and monoglucoside proportions between the other treatments and the control. The concentrations of diglucosides and monoglucoside in berries from T1, T2 and T3 were significantly lower than the control, and T6 also decreased the monoglucoside concentration significantly. At maturity, T3 and T7 increased the proportions of 3', ''-substituent anthocyanins in grapes compared to the control but decreased those of 3'-substituent anthocyanins. The pattern of hydroxylase anthocyanin proportions in $\mathrm{T} 3$ and $\mathrm{T} 7$ berries were opposite of that observed in T2 and T6. T1, T2, T3 and T6 significantly decreased the concentrations of 3',5'-substituent anthocyanins. T1, T2, T3, T6, T7 and T8 increased the
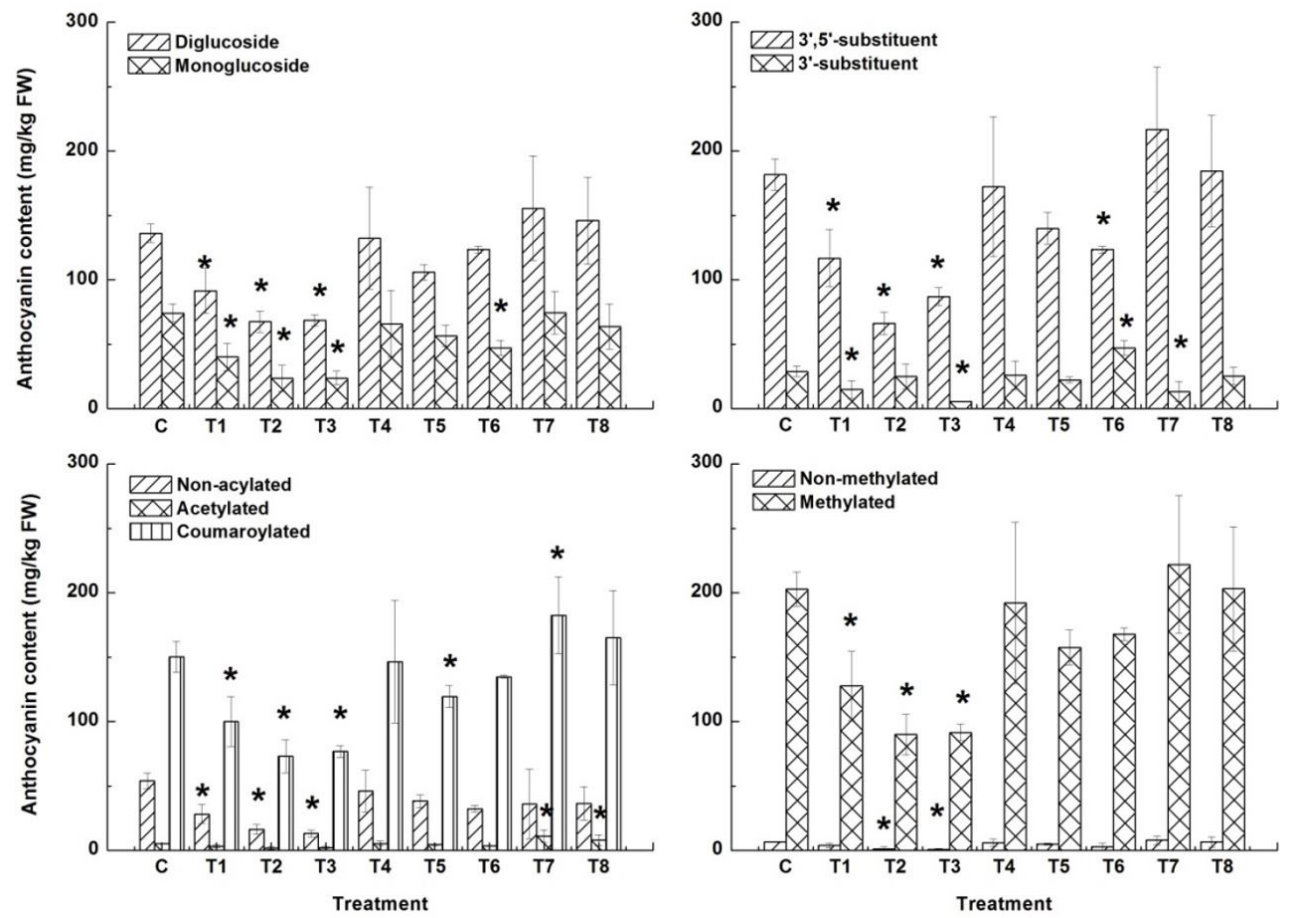

Figure 3. The concentration (mg/kg FW) of different modified anthocyanins in berry skins of 'Kyoho'* indicate significant difference between control and treatments at $\mathrm{P}<0.05$.

Table 1. The proportion (\%) of different modified anthocyanins and total anthocyanin concentration (mg/kg FW) in berry skins of 'Kyoho'.

\begin{tabular}{|c|c|c|c|c|c|c|c|c|c|}
\hline Anthocyanins & Control & $\mathrm{T} 1$ & $\mathrm{~T} 2$ & T3 & $\mathrm{T} 4$ & T5 & T6 & T7 & T8 \\
\hline Diglucosides & $64.72 \pm 1.65 \mathrm{a}$ & $69.74 \pm 2.02 \mathrm{a}$ & $74.79 \pm 6.40 \mathrm{~b}$ & $74.40 \pm 4.24 b$ & $67.17 \pm 1.89 \mathrm{a}$ & $65.28 \pm 2.05 \mathrm{a}$ & $72.39 \pm 2.82 \mathrm{a}$ & $67.43 \pm 2.14 \mathrm{a}$ & $69.64 \pm 2.48 \mathrm{a}$ \\
\hline Monoglucoside & $35.28 \pm 1.65 b$ & $30.26 \pm 2.02 b$ & $25.21 \pm 6.40 \mathrm{a}$ & $25.60 \pm 4.24 \mathrm{a}$ & $32.83 \pm 1.89 b$ & $34.72 \pm 2.05 b$ & $27.61 \pm 2.82 b$ & $32.57 \pm 2.14 b$ & $30.36 \pm 2.48 b$ \\
\hline 3',5'-substituent & $86.17 \pm 1.80 \mathrm{~b}$ & $88.94 \pm 3.65 b$ & $73.08 \pm 6.00 \mathrm{a}$ & $94.08 \pm 0.45 c$ & $87.18 \pm 1.17 \mathrm{~b}$ & $86.21 \pm 0.35 b$ & $72.39 \pm 2.82 \mathrm{a}$ & $94.56 \pm 2.22 c$ & $88.03 \pm 0.43 b$ \\
\hline 3'-substituent & $13.83 \pm 1.80 \mathrm{~b}$ & $11.06 \pm 3.65 b$ & $26.92 \pm 6.00 c$ & $5.92 \pm 0.45 a$ & $12.82 \pm 1.17 b$ & $13.79 \pm 0.35 b$ & $27.61 \pm 2.82 c$ & $5.44 \pm 2.22 \mathrm{a}$ & $11.97 \pm 0.43 b$ \\
\hline Non-acylated & $25.79 \pm 2.68 c$ & $21.34 \pm 1.62 \mathrm{bc}$ & $17.89 \pm 1.05 \mathrm{ab}$ & $14.25 \pm 1.86 \mathrm{a}$ & $23.19 \pm 0.92 b c$ & $23.64 \pm 1.11 b c$ & $18.95 \pm 1.13 \mathrm{ab}$ & $14.34 \pm 8.95 \mathrm{a}$ & $17.22 \pm 2.42 \mathrm{ab}$ \\
\hline Acetylated & $2.53 \pm 0.12 \mathrm{a}$ & $2.38 \pm 0.30 \mathrm{a}$ & $1.84 \pm 0.71 \mathrm{a}$ & $2.35 \pm 1.11 \mathrm{a}$ & $2.74 \pm 0.01 \mathrm{a}$ & $2.74 \pm 0.16 a$ & $2.08 \pm 0.11 \mathrm{a}$ & $5.15 \pm 2.95 b$ & $3.79 \pm 1.98 \mathrm{ab}$ \\
\hline Coumaroylated & $71.41 \pm 3.23 a$ & $76.28 \pm 1.62 b$ & $80.27 \pm 1.29 c$ & $83.40 \pm 2.96 \mathrm{~cd}$ & $74.07 \pm 0.93 \mathrm{ab}$ & $73.62 \pm 1.22 \mathrm{ab}$ & $78.97 \pm 1.24 \mathrm{bc}$ & $80.50 \pm 6.78 c$ & $79.00 \pm 1.42 b c$ \\
\hline Non-methylated & $3.20 \pm 0.16 b c$ & $2.99 \pm 0.39 b c$ & $0.40 \pm 0.26 \mathrm{ab}$ & $0.26 \pm 0.08 \mathrm{a}$ & $2.98 \pm 0.33 b c$ & $3.01 \pm 0.19 b c$ & $0.65 \pm 0.10 \mathrm{abc}$ & $3.37 \pm 0.81 c$ & $3.03 \pm 0.71 b c$ \\
\hline Methylated & $96.40 \pm 0.38 \mathrm{a}$ & $97.01 \pm 1.39 \mathrm{ab}$ & $99.60 \pm 0.26 b c$ & $99.74 \pm 0.08 c$ & $97.02 \pm 0.33 \mathrm{ab}$ & $96.99 \pm 0.19 \mathrm{ab}$ & $99.35 \pm 0.10 \mathrm{abc}$ & $96.63 \pm 0.81 \mathrm{a}$ & $96.97 \pm 1.71 \mathrm{ab}$ \\
\hline $\begin{array}{l}\text { Total } \\
\text { concentration }\end{array}$ & $210.29 \pm 13.04 c$ & $131.65 \pm 27.58 \mathrm{ab}$ & $91.18 \pm 17.38 \mathrm{a}$ & $92.31 \pm 7.09 \mathrm{a}$ & $198.19 \pm 65.47 c$ & $162.37 \pm 14.18 b c$ & $170.66 \pm 3.17 b c$ & $229.92 \pm 56.45 c$ & $209.67 \pm 50.23 c$ \\
\hline
\end{tabular}

Note: Different small letter between berries under shading treatments indicate significant differences at $5 \%$ level $(\mathrm{P}<0.05)$. 
proportions of coumaroylated anthocyanins compared to the control. It is worth noting that $\mathrm{T} 7$ increased the proportions and concentrations of acetylated and coumaroylated anthocyanins. The concentrations of methylated anthocyanins T1, T2 and T3 were lower than that in the control, but they exhibited higher proportions of methylated anthocyanins, except T1. T7 and T8 increased the proportions and concentrations of 3,5'-substituent and acylated anthocyanins, respectively.

\section{Discussion}

The practice of preharvest bagging has been previously used in several fruit crops to delay ripening, reduce splitting and mechanical damage and improve marketability. Bagging can change the microclimate of clusters, especially with regard to sunlight. Relative light intensity measurements indicated that the bags and umbrellas used in this study effectively excluded sunlight from clusters, except nonwoven and transparent bags. Yellow bags had only an approximately $7 \%$ relative light intensity, but nonwoven and transparent bags increased relative light intensity by approximately $10-30 \%$. This was caused by more light reflection and transmission from small holes on the surface of nonwoven and transparent bags. For the same color bags, those with umbrellas showed a lower relative light intensity than the individual bagging treatments. Son \& Lee (2008) found that relative light intensity was high in the order of white bags $>$ yellow bags $>$ blue bags. When the relative light intensity of the bag was high, the soluble solids content was higher. In this study, the relative light intensity of bags was highest to lowest in the following order: nonwoven bags $>$ transparent bags $>$ white bags $>$ green bags $>$ yellow bags. Zhou \& Guo (2005) found that the sugar content of 'Red Globe' bagged berries was significantly higher at the late stage of fruit development. In the present study, the effect of bagging and a combination of umbrella and bags on berry growth, sugar content and titratable acidity in grapes was shown to be variable when the bag color and texture were different. In addition, white, green, yellow and umbrella+white bags significantly decreased the soluble solids content, which could be due to shading effects and used to delay the ripening process and increase the time grapes remain on the vines.

Although genetically controlled, anthocyanin biosynthesis in grape berry skin is greatly influenced by many environmental factors, especially sunlight (Human \& Bindon, 2008). The effects of shading clusters or excluding sunlight from clusters have been extensively documented. The consensus view has been that shading clusters or excluding sunlight from clusters reduced anthocyanins and improved color development, while a higher light intensity resulted in increased inferior color development (Jeong et al., 2004; Cortell \& Kennedy, 2006). However, Zhang et al. (2014) found that black-bag treatment significantly increased the anthocyanin content. In this study, despite differences in berry and skin fresh weight and soluble solids content, bagging from veraison to harvest, during which grape berries accumulate anthocyanins, resulted in a significant decrease in the anthocyanin concentration of berry skins treated with white, green and yellow bags. However, nonwoven and transparent bags had no effect on total anthocyanin concentrations, although they presented a higher relative light intensity compared with the control. In addition, the total anthocyanin concentration and concentrations of individual anthocyanins were decreased for berries treated with green and yellow bags. These results showed that different colored bags and umbrellas can alter the anthocyanin profile as well as influence the berry color. Jeong et al. (2004) examined the effects of shading on the expression of anthocyanin pathway genes in 'Cabernet Sauvignon' and found that shading suppressed anthocyanin accumulation and affected the transcription of both UFGT and other pathway genes. Thus, the effects of different color and texture bags and bagging combination with umbrellas on the expression of anthocyanin pathway genes warrant further study.

Normally, anthocyanin diglucosides are more stable than their monoglucoside counterparts but are more susceptible to browning and are less colored (Kim et al., 2010). In the present study, grapes treated with green and yellow bags showed significantly higher proportions of diglucosides than the control. Thus, the bags with strong shading effects could change the proportion of glucosides and depigmentize grape color.

In addition, 3'5'-substituted anthocyanins (delphinidin, malvidin and petunidin) and 3'-substituted (cyanidin and peonidin) anthocyanins always produced blue and red hues, respectively (Kong et al., 2003), and some studies have shown that their proportions changed in response to sunlight exposure or shading treatments. In cv. 'Shiraz', decreased sunlight showed decreases in the proportions of delphinidin-, petunidin- and malvidin-glucosides and an increase in peonidin-glucosides (Downey et al., 2004). In the present study, the proportions of 3',5'-substituent anthocyanins significantly increased in berries treated with yellow and umbrella+nonwoven bags and proportions of 3'-substituent anthocyanins decreased in those two treatments. White, yellow, green bags significantly decreased the concentrations of 3',5'-substituent anthocyanins. Thus, the clusters processed by those treatments showed much stronger red than purple hues. This indicated that suppression of 3',5'-substituent anthocyanin biosynthesis resulted from shading by some bagging treatments, which produced grapes with uneven red color.

Anthocyanins can also be classified into nonmethylated (delphinidin- and cyanidin-derivatives) and methylated (petunidin-, peonidin- and malvidin-derivatives). Because of the phenolic $B$ ring substitution, peonidin and malvidin are relatively stable and represent the major anthocyanin pools in mature grapes. In the present study, green and yellow bags increased the proportions of methylated anthocyanins in grape skins. This suggested that sunlight is not needed to promote the methylation level of anthocyanin at maturity. Haselgrove et al. (2000) studied the effect of shading on 'Shiraz' phenolic composition, and the results showed that there was a shift from glucoside anthocyanins to acylated forms. All the treatments in this study increased the proportions of coumaroylated anthocyanins except nonwoven and transparent bags. It is worth noting that umbrella+nonwoven bags increased the proportions and concentrations of acetylated and coumaroylated anthocyanins. All of the results confirmed that a lower light environment could potentially increase acylated anthocyanins, but the distinction between the effects of light and temperature was not achieved. 


\section{Conclusion}

Bagging or the combination of umbrella and bags on anthocyanin accumulation in berry skins of 'Kyoho' grape imposed in this study showed inconsistent effects, which depended on colors, materials of bags and using an umbrella or not. Compared with the control, the inhibition effects of white, green and yellow bags on soluble solids content and total and individual anthocyanin concentration in 'Kyoho' grapes reached significant levels, and the levels in grapes treated with green and yellow bags were the most significant among treatments. These bags were associated with a significant reduction in the relative light intensity and were used to delay the ripening process and increase the time grapes remained on the vines. The plastic umbrella used in this study also reduced the relative light intensity and produced more even-colored clusters. White, green, and yellow bags and umbrellas could significantly increase some stable anthocyanin proportions to varying degrees.

\section{Acknowledgements}

This study was funded by a grant from the state Science and Technology Support Program (Grant No. 2014BAD16B05), Modern Agriculture (Grape) Industry and Technology System Special Funding (Grant No. CARS-29-20), Basal Research Fund of Guangxi Academy of Agricultural Sciences (Grant No. Guinongke 2015YT82).

\section{References}

Cortell, J. M., \& Kennedy, J. A. (2006). Effect of shading on accumulation of flavonoid compounds in (Vitis Vinifera L.) pinot noir fruit and extraction in a model system. Journal of Agricultural and Food Chemistry, 54(22), 8510-8520. http://dx.doi.org/10.1021/jf0616560. PMid:17061828.

Downey, M. O., Harvey, J. S., \& Robinson, S. P. (2004). The effect of bunch shading on berry development and flavonoid accumulation in shiraz grapes. Australian Journal of Grape and Wine Research, 10(1), 55-73. http://dx.doi.org/10.1111/j.1755-0238.2004.tb00008.x.

Fujita, A., Soma, N., Goto-Yamamoto, N., Mizuno, A., Kiso, K., \& Hashizume, K. (2007). Effect of shading on proanthocyanidin biosynthesis in the grape berry. Journal of the Japanese Society for Horticultural Science, 76(76), 112-119. http://dx.doi.org/10.2503/ jjshs.76.112.

Gao, Y., \& Cahoon, G. A. (1994). Cluster shading effects on fruit quality, fruit skin color, and anthocyanin content and composition in reliance (Vitis hybrid). Vitis, 33, 205-209.

Haselgrove, L., Botting, D., Heeswijck, R. V., Høj, P. B., Dry, P. R., Ford, C., \& Land, P. G. I. (2000). Canopy microclimate and berry composition: the effect of bunch exposure on the phenolic composition of Vitis vinifera L cv. Shiraz grape berries. Australian Journal of Grape and Wine Research, 6(2), 141-149. http://dx.doi. org/10.1111/j.1755-0238.2000.tb00173.x.

He, J. J., Liu, Y. X., Pan, Q. H., Cui, X. Y., \& Duan, C. Q. (2010). Different anthocyanin profiles of the skin and the pulp of yan7 (Muscat Hamburg x Alicante Bouschet) grape berries. Molecules, 15(3), 1141-1153. http://dx.doi.org/10.3390/molecules15031141. PMid:20335969.

Human, M. A., \& Bindon, K. A. (2008). Interactive effect of ethephon and shading on the anthocyanin composition of Vitis vinifera L. cv. crimson seedless. South African Journal of Enology and Viticulture, 29(1), 50-58.

Jeong, S. T., Goto-Yamamoto, N., Kobayashi, S., \& Esaka, M. (2004). Effects of plant hormones and shading on the accumulation of anthocyanins and the expression of anthocyanin biosynthetic genes in grape berry skins. Plant Science, 167(2), 247-252. http://dx.doi. org/10.1016/j.plantsci.2004.03.021.

Kim, M., Yoon, S. H., Jung, M., \& Choe, E. (2010). Stability of meoru (Vitis coignetiea) anthocyanins under photochemically produced singlet oxygen by riboflavin. New Biotechnology, 27(4), 435-439. http://dx.doi.org/10.1016/j.nbt.2010.01.003. PMid:20085831.

Kong, J. M., Chia, L. S., Goh, N. K., Chia, T. F., \& Brouillard, R. (2003). Analysis and biological activities of anthocyanins. Phytochemistry, 64(5), 923-933. http://dx.doi.org/10.1016/S0031-9422(03)00438-2. PMid:14561507.

Koyama, K., \& Goto-Yamamoto, N. (2008). Bunch shading during different developmental stages affects the phenolic biosynthesis in berry skins of 'Cabernet Sauvignon' grapes. Journal of the American Society for Horticultural Science, 133(6), 743-753. http://dx.doi. org/10.21273/JASHS.133.6.743.

Li, J.-H., Guan, L., Fan, P.-G., Li, S.-H., \& Wu, B.-H. (2013). Effect of sunlight exclusion at different phenological stages on anthocyanin accumulation in red grape clusters. American Journal of Enology and Viticulture, 64(3), 349-356. http://dx.doi.org/10.5344/ajev.2013.12130.

Matus, J. T., Loyola, R., Vega, A., Peña-Neira, A., Bordeu, E., ArceJohnson, P., \& Alcalde, J. A (2009). Post-veraison sunlight exposure induces myb-mediated transcriptional regulation of anthocyanin and flavonol synthesis in berry skins of vitis vinifera. Journal of Experimental Botany, 60(3), 853-867. http://dx.doi.org/10.1093/ jxb/ern336. PMid:19129169.

Son, I. C., \& Lee, C. H. (2008). The effects of bags with different light transmittance on the berry cracking of grape 'kyoho'. Horticulture, Environment and Biotechnology, 49(2), 98-103.

Sun, R. Z., Cheng, G., Li, Q., He, Y. N., Wang, Y., Lan, Y. B., Li, S. Y., Zhu, Y. R., Song, W. F., Zhang, X., Cui, X. D., Chen, W., \& Wang, J. (2017). Light-induced variation in phenolic compounds in Cabernet Sauvignon grapes (Vitis vinifera L.) Involves extensive transcriptome reprogramming of biosynthetic enzymes, transcription factors, and phytohormonal regulators. Frontiers in Plant Science, 8, 547. http:// dx.doi.org/10.3389/fpls.2017.00547. PMid:28469625.

Tarara, J. M., Lee, J., Spayd, S. E., \& Scagel, C. F. (2008). Berry temperature and solar radiation alter acylation, proportion, and concentration of anthocyanin in Merlot grapes. American Journal of Enology and Viticulture, 59(5), 235-247.

Wang, B., He, J., Duan, C., Yu, X., Zhu, L., Xie, Z., Zhang, C., Xu, W., \& Wang, S. (2012). Root restriction affects anthocyanin accumulation and composition in berry skin of 'kyoho' grape (Vitis vinifera, L. $\times$ Vitis labrusca, L.) during ripening. Scientia Horticulturae, 137, 20-28. http://dx.doi.org/10.1016/j.scienta.2011.10.006.

Wang, S., Okamoto, G., Hirano, K., Lu, J., \& Zhang, C. (2001). Effects of restricted rooting volume on vine growth and berry development of kyoho grapevines. American Journal of Enology and Viticulture, 52(3), 248-253.

Zhang, L., Jia, Y., Wang, J. Y., Tao, J. M., \& University, N. A. (2014). Effects of bagging on anthocyanins component and biosynthetic genes expression in 'Manicure Finger' grape. Guoshu Xuebao, 31(6), 1032-1039.

Zhou, X. B., \& Guo, X. W. (2005). Effects of bagging on the fruit sugar metabolism and invertase activities in Red Globe grape during fruit development. Guoshu Xuebao, 22(3), 207-210. 


\section{Supplementary Material}

Supplementary material accompanies this paper.

Figure S1. Experimental design of this study. Control: clusters exposed to sunlight during the entire developmental period; T1: clusters excluded from sunlight from the beginning veraison ( 8 weeks after anthesis) by use of white bags;T2: clusters excluded from sunlight from the beginning veraison ( 8 weeks after anthesis) by use of green bags; T3: clusters excluded from sunlight from the beginning veraison ( 8 weeks after anthesis) by use of yellow bags; T4: clusters excluded from sunlight from the beginning veraison ( 8 weeks after anthesis) by use of non-woven bags; T5: clusters excluded from sunlight from the beginning veraison ( 8 weeks after anthesis) by use of transparent bags; T6: clusters excluded from sunlight from the beginning veraison (8 weeks after anthesis) by use of umbrellas and white bags; T7: clusters excluded from sunlight from the beginning veraison ( 8 weeks after anthesis) by use of umbrellas and non-woven bags; T8: clusters excluded from sunlight from the beginning veraison (8 weeks after anthesis) by use of umbrellas and transparent bags.

Table S1. Some physical and chemical characteristics of 'Kyoho' berries under shading treatments

Table S2. The chromatography and mass spectrometry information of anthocyanins found in berries of 'Kyoho'

This material is available as part of the online article from http://www.scielo.br/cta 